\title{
BMJ Open What are healthcare providers' understandings and experiences of compassion? The healthcare compassion model: a grounded theory study of healthcare providers in Canada
}

Shane Sinclair, ${ }^{1,2}$ Thomas F Hack, ${ }^{3,4,5}$ Shelley Raffin-Bouchal, ${ }^{1}$
Susan McClement,,
Aynharan Sinnarajah, ${ }^{2,8}$ Harvey Max ${ }^{2,4}$ Chochinov ${ }^{3,9}$
To cite: Sinclair S, Hack TF, Raffin-Bouchal S, et al. What are healthcare providers' understandings and experiences of compassion? The healthcare compassion model: a grounded theory study of healthcare providers in Canada. BMJ Open 2018;0:e019701. doi:10.1136/ bmjopen-2017-019701

- Prepublication history for this paper is available online. To view these files, please visit the journal online (http://dx.doi. org/10.1136/bmjopen-2017019701).

Received 21 September 2017 Revised 22 January 2018 Accepted 9 February 2018

Check for updates

For numbered affiliations see end of article.

Correspondence to

Dr Shane Sinclair;

sinclair@ucalgary.ca

\section{ABSTRACT}

Background Healthcare providers are considered the primary conduit of compassion in healthcare. Although most healthcare providers desire to provide compassion, and patients and families expect to receive it, an evidence-based understanding of the construct and its associated dimensions from the perspective of healthcare providers is needed. Objectives The aim of this study was to investigate healthcare providers' perspectives and experiences of compassion in order to generate an empirically derived, clinically informed model.

Design Data were collected via focus groups with frontline healthcare providers and interviews with peernominated exemplary compassionate healthcare providers. Data were independently and collectively analysed by the research team in accordance with Straussian grounded theory.

Setting and participants 57 healthcare providers were recruited from urban and rural palliative care services spanning hospice, home care, hospital-based consult teams, and a dedicated inpatient unit within Alberta, Canada.

Results Five categories and 13 associated themes were identified, illustrated in the Healthcare Provider Compassion Model depicting the dimensions of compassion and their relationship to one another. Compassion was conceptualised as - a virtuous and intentional response to know a person, to discern their needs and ameliorate their suffering through relational understanding and action. Conclusions An empirical foundation of healthcare providers' perspectives on providing compassionate care was generated. While the dimensions of the Healthcare Provider Compassion Model were congruent with the previously developed Patient Model, further insight into compassion is now evident. The Healthcare Provider Compassion Model provides a model to guide clinical practice and research focused on developing interventions, measures and resources to improve it.

\section{BACKGROUND}

Compassion is considered a vital component of quality healthcare. Healthcare providers
Strengths and limitations of this study

- This grounded theory study delineates the key dimensions of compassion from direct reports of a large qualitative sample $(n=57)$ consisting of frontline healthcare providers, nominated exemplary compassionate healthcare providers and key stakeholders across three distinct data collection phases.

- A healthcare provider definition and empirical model of compassion extends the largely theoretical nature of the compassion literature to a clinically informed and clinically relevant model that can serve as a framework for policy, practice, education and research.

- By recruiting healthcare providers working primarily in palliative care, substantial variance in perspectives and experiences of compassion based on other practice settings, patient populations, subspecialties and cultures were not necessarily captured.

- By using purposive, snowball and theoretical sampling techniques, our sample may have been overly represented by like-minded individuals who had an affinity towards the topic and their ability to provide compassion.

(HCPs) are increasingly recognised as the primary, frontline conduits of compassionate care, and not surprisingly, the first target of criticism when compassion is lacking. ${ }^{1-8}$ Despite their instrumental role in delivering compassionate care within the healthcare system, research investigating HCPs' understandings and experiences of providing compassionate care directly is nascent. ${ }^{9}$ Work investigating nursing ${ }^{10-13}$ and physician perspectives ${ }^{14}{ }^{15}$ have begun to advance the field from what was previously a largely theoretical body of knowledge towards an evidence and clinically informed field of research. The current study is aimed 
to extend this work in order to develop an empirically derived, clinically informed, model of compassion. It intends to outline key dimensions of compassionate care in the context of healthcare and also to characterise the nature of compassion from the perspective of interdisciplinary HCPs who are charged and challenged to provide it. Earlier research largely use a priori definitions of compassion, or definitions based on factors or situations HCPs associate with compassion. In contrast, we began by asking HCPs directly about their understanding of compassion. Obtaining direct participant reports on the construct of interest is recognised as an important step in establishing construct validity particularly for subjective and relational constructs such as compassion, ${ }^{16-18}$ significantly effecting the models, measures and research that are produced from them.

Recently, our research team identified a similar research need-a lack of direct patient accounts on the nature of compassion in healthcare-leading to the development of an empirically derived, patient informed model of compassion. ${ }^{19}$ This study generated the following patient informed definition of compassion: 'a virtuous response that seeks to address the suffering and needs of a person through relational understanding and action'. ${ }^{19}$ Much like the dearth of patient perspectives in the literature, we were able to identify only a few studies investigating HCP perspectives of compassion, most of which used predetermined researcher generated definitions rather than establishing construct validity from the perspective of individuals actually involved in providing compassion. ${ }^{10} 11132021$ Together, these and other published studies identified a wide array of behaviours, skills and attitudes associated with compassion at the bedside, including: relating to the patient as an individual ${ }^{21-26}$; reacting to suffering ${ }^{132127}$; presence $^{13}$; giving time and listening ${ }^{13232829}$; understanding patients' feelings ${ }^{13}{ }^{28}{ }^{30}$; confronting $^{13}$; caring $^{13}$; a moral virtue $^{28}$; intelligent kindness ${ }^{31}$; empathy ${ }^{11272830}$; assisting patients to make their own decisions ${ }^{28}$; and acting in patients' best interests. ${ }^{28}$ In the few studies that asked participants to define compassion directly, psychotherapists identified it as 'connecting the clients suffering and promoting change through action' ${ }^{20}$ A group of healthcare stakeholders defined compassion as "the combination of underpinning emotions (such as sympathy and empathy), with altruistic values (particularly a desire to help others), which together motivated an individual to take action that would ultimately be experienced as 'care by the recipient'.," ${ }^{32}$ While these studies provide insight into conceptualisations of compassion from the perspective of providers, they are yet limited in their: representativeness of interdisciplinary perspectives; specificity in identifying the key dimensions of compassion and their relationship to one another; delineation of compassion to related concepts such as care, empathy and sympathy; and methodological rigour. ${ }^{9} 334$

The consequences of these issues extend beyond the realm of scholarship, having direct application to healthcare education and practice. Increasingly, governments, patients and healthcare institutions consider compassion a clinical necessity. Compassion has been considered a standard of care, ${ }^{45}$ an admission requirement for healthcare education ${ }^{35-37}$ and a practice competency. ${ }^{25}$ As a result, educators, HCPs and trainees are encouraged, expected and increasingly held accountable for their competency in providing compassion-but as yet without the benefit of a rubric defining and delineating the key attitudes, knowledge, skills and behaviours that are to be taught and learnt.

To address these gaps, this grounded theory study investigated the perspectives and experiences of HCPs on the construct of compassion, in order to develop an empirical model illustrating its key dimensions and their relationship to one another.

\section{METHODS}

\section{Study population}

After receiving approval to conduct this study from the University of Calgary Conjoint Health Research Ethics Board (number: REB 15-1999), HCPs were recruited through convenience sampling, snowball sampling and theoretical sampling. ${ }^{38}$ With theoretical sampling, certain types of participants (gender, ethnicity, profession) are sampled to ensure a heterogeneous sample and to address gaps or underdeveloped facets of the emerging model (such as underdeveloped categories or themes, and unanticipated findings). HCPs were recruited between October 2015 and September 2016 from the palliative care services of the Calgary Zone in Alberta, Canada. The services include urban and rural hospice, home care, hospital-based consult teams and a dedicated inpatient palliative care unit. HCPs were eligible to participate if they: (1) were at least 18 years of age; (2) were able to read and speak English; (3) worked in palliative care for at least 6 months; and (4) were able to provide written informed consent. While all participants currently worked in palliative care, many of the study participants had additional, extensive clinical experience in areas of clinical care beyond palliative care. Participants' questions or concerns were addressed, and consent was obtained prior to participation in focus groups and interviews. Although sample sizes are not predetermined in qualitative studies, based on our own research involving similar methodology, ${ }^{19} 3940$ we aimed to recruit approximately 50 HCPs. Ultimately, 57 participants were required to reach data saturation (table 1 ).

\section{Data collection}

Data were collected via an interview guide (boxes 1-3) using focus groups and one-on-one semistructured interviews across three study stages. In the first stage, 35 frontline HCPs participated in one of seven focus groups, ranging from 1 to 1.5 hours in duration. Meetings were held in a private conference room at their place of work. The purpose of the focus groups was to 
Table 1 Demographic information (numbers expressed as percentages and $(n))$

\begin{tabular}{lc}
\hline Mean age (years) & 48.6 \\
$\quad$ Men & $14(8)$ \\
\hline Women & $86(49)$ \\
$\begin{array}{l}\text { Mean number of years in palliative care } \\
\text { (range) }\end{array}$ & 11.8 \\
\hline
\end{tabular}

Employment status*

\begin{tabular}{|c|c|}
\hline Full-time & $57.8(33)$ \\
\hline Part-time & $33.3(19)$ \\
\hline Casual & $7.0(4)$ \\
\hline \multicolumn{2}{|l|}{ Profession } \\
\hline Registered nurse & $45.6(26)$ \\
\hline Physicians & $22.8(13)$ \\
\hline Healthcare aide & $7.0(4)$ \\
\hline Spiritual care specialist & $5.2(3)$ \\
\hline Unit clerk & $3.5(2)$ \\
\hline Occupational therapist & $3.5(2)$ \\
\hline Licensed practical nurse & $3.5(2)$ \\
\hline Housekeeper & $1.7(1)$ \\
\hline Social worker & $1.7(1)$ \\
\hline Psychologist & $1.7(1)$ \\
\hline Respiratory therapist & $1.7(1)$ \\
\hline Physiotherapist & $1.7(1)$ \\
\hline \multicolumn{2}{|l|}{ Care setting } \\
\hline Home care & $29.8(17)$ \\
\hline Hospice & $26.3(15)$ \\
\hline Hospital dedicated palliative care unit & $21.0(12)$ \\
\hline Hospital palliative care consult service & $14.0(8)$ \\
\hline Palliative care administrator & $7.0(4)$ \\
\hline $\begin{array}{l}\text { Outpatient oncology palliative care } \\
\text { consult service }\end{array}$ & $5.2(3)$ \\
\hline Rural palliative care consult service & $5.2(3)$ \\
\hline Other & $1.7(1)$ \\
\hline \multicolumn{2}{|l|}{ Religious affiliation* } \\
\hline Christian & $52.6(30)$ \\
\hline Buddhist & $7.0(4)$ \\
\hline Jewish & $3.5(2)$ \\
\hline Muslim & $1.7(1)$ \\
\hline Hindu & $1.7(1)$ \\
\hline None & $31.5(18)$ \\
\hline \multicolumn{2}{|l|}{ Religious and spiritual status* } \\
\hline Spiritual and religious & $33.3(19)$ \\
\hline Spiritual but not religious & $56.1(32)$ \\
\hline None & $8.7(5)$ \\
\hline
\end{tabular}

*The total for these categories is less than $100 \%$ due to nonresponse by participants.

†The total for these categories is more than $100 \%$ due to some participants working in multiple care settings.

\section{Box 1 Stage 1: Focus group guiding questions}

1. Based on your professional and personal experience, what does compassion mean to you?

2. Can you give me an example of when you felt you provided or witnessed care that was compassionate? (What do you feel were the key aspects of these interactions?)

3. What do you feel are the major influencers of compassionate care in your practice?

4. What do you feel inhibits your ability to provide compassionate care?

5. Do you think patients and/or family members influence the provision of compassionate care? (How or how not?) (If yes, what characteristics of patients and/or families, do you feel facilitate or inhibit compassionate care?)

6. What advice would you give other healthcare providers on providing compassionate care?

7. Do you think we can train people to be compassionate? (If so, how?)

8. Based on your experience what role, if any, do you feel compassion has in alleviating end of life distress? (What happens when compassionate care is lacking?)

9. What impact does providing compassionate care have on you personally and professionally?

10. Is there anything related to compassion that we have not talked about today that you think is important or were hoping to talk about?

obtain an understanding of the perspective of a broad cohort of interdisciplinary care providers involved in direct patient care. The second stage involved interviews with HCPs who were nominated by their peers as exemplary compassionate HCPs in order to elicit an advanced understanding of the qualities, skills knowledge and behaviours associated with compassion from the perspective of clinical experts. Exemplary compassionate care providers were nominated by focus group participants via a question within the study demographic questionnaire that asked them to nominate up to two of their interdisciplinary peers whom they considered to be exemplary compassionate HCPs. A total of 15 individual interviews were conducted in a private room at their place of work, with three of these individuals having also participated in stage 1 focus groups. The final stage of data collection occurred through two focus groups with stage 1 and 2 study participants $(n=5)$ and key stakeholders $(n=10)$ (administrators, clinical leads and health faculty educators) in order to assess the validity of the model and facilitate knowledge translation and future research directions. Stage 3 focus groups were also used to further fulfil the criteria for rigour in qualitative studies: fit (categories should emerge from the data and not the pre-existing perspective of the researchers); work (the ability for the theory to explain and interpret behaviour in the area of study); relevance (the theory is relevant to clinical care); and modifiability (that the theory is adaptable to different contexts and as new data become available).$^{41}$ All focus groups and interviews were conducted by an experienced qualitative interviewer who was not a member of 


\section{Box 2 Stage 2: Interview guiding questions}

1. You have been identified by your peers as possessing great skill in providing compassionate care. What do you feel might be some of the reasons for this recognition? (Why do you think others identify you as a compassionate healthcare provider?)

2. In your own terms, how would you define compassion? (What does compassion mean to you?)

3. How did you become a compassionate caregiver? (What beliefs, situations, individuals and/or life experiences in your life and practice do you feel have informed your understanding and provision of compassionate care? Have you always been that way? Were you always like that? How did you learn it? Can it be learned?)

4. If you reflect back on your current position, can you walk me through the best example of when you provided compassionate care? (What constitutes compassionate care? Please guide me through the process of this encounter in a sequential fashion, highlighting the key components of this interaction from the initial approach to the consequences of this interaction.)

5. Based on your professional and personal experiences, what shapes your compassionate care?

6. If you were responsible for training students in compassionate care, how would you go about it? (What would you teach them?)

7. Is there anything that gets in the way of your ability to provide compassionate care?

8. How do patients and/or families influence your ability to provide compassionate care? (What characteristics of patients and/or families, do you feel facilitate or inhibit compassionate care?)

9. A number of participants have identified the healthcare system as being a significant factor in delivering compassionate care. From your perspective, how does/can the healthcare system facilitate or inhibit compassionate care?

10. In light of the things you've just identified as facilitators and barriers, what suggestions would you have for enhancing compassion at a systems level? (Where and what would you focus your efforts on in order to enhance compassion at a systems level?)

11. From what you've told me so far, it sounds like compassionate care is important. So what happens (to patients, families or HCPs) when compassionate care is lacking?

12. What impact does providing compassionate care have on you personally and professionally?

13. Our focus group participants, previous studies and review of the literature have reported how critical and fundamental compassion is to providing quality patient care, but we also know that compassionate care varies. So given all that we know about the importance of compassionate care, why aren't healthcare providers more compassionate?

14. Before we end, given all we've talked about, I just want to revisit one of the first questions I asked, which is how do you personally define compassion? (In light of our discussion, what does compassion mean to you?)

15. Is there anything related to compassion that we have not talked about today that you think is important or were hoping to talk about?

the analysis team, with the exception of the first two focus groups in stages 1 and 3, which were conducted by the principal investigator (SS) for training and standardisation purposes. The interviewer was neither a member of the clinical team and had no previous relationship with study participants. In addition to a formal orientation and protocol training session in accordance with Straussian

\section{Box 3 Stage 3: Focus group guiding questions}

1. Does the healthcare provider model of compassion make sense to you? (Does it resonate with you?) (Why or Why not?)

2. Do you feel there is anything missing from the model?

3. How do you feel this model might be relevant to you and your work?

4. How do you suggest the model might be integrated into healthcare practice and education?

5. Is there anything related to the model that we have not talked about today that you think is important or were hoping to talk about?

grounded theory, we mitigated against interviewer bias by using a standardised interview guide and instructing the interviewer to focus on active listening, participant responses and predetermined prompting questions (box 1). The focus groups and interviews were audio-recorded and transcribed verbatim, with contextual content (such as emotions and non-verbal communication) being recorded in the form of field notes. The verbatim transcripts were independently verified against the audio recording by the interviewer and a member of the analysis team (SS). The fidelity of each focus group and interview session was further ensured by having the analysis team analyse the interviewer's adherence to the protocol and the performance of the interview questions in each transcript, and providing feedback and correction.

\section{Data analysis}

This study was guided by Straussian grounded theory, an inductive, iterative, qualitative method that aims to define and construct an empirically grounded account of a topic grounded in study data within a naturalistic setting. ${ }^{38} 4142$ Grounded theory is a particularly useful method when investigating social processes related to complex phenomena that are based on the subjective experience of participants. ${ }^{41}{ }^{42}$ Five members of the research team, who have extensive research and teaching experience in qualitative methods (SS, TFH, SM, SRB, KS), analysed the data in accordance with the three stages of analysis. The analysis team comprised two men and three women and professionally consisted of three nurses, a psychologist and a spiritual care provider. The first stage, open coding, involved each individual independently analysing each transcript in a line-by-line manner. Individual codes were recorded in the margin, with subsequent codes being compared and contrasted with previous codes - an analytical process known as the constant comparative technique.$^{38}$ After independently analysing each set of two to three transcripts, the analysis team (SS, TFH, SM, SRB, KS) met to compare their individual codes. They read through each transcript again in a line-by-line fashion, settling differences between individual's codes and delineating incidences in the transcript that were non-specific to compassion through a process of consensus. This produced a 'master' coded transcript for each interview and focus group. Rigour was further assured by having three physician members (AS, NAH, HMC) of the study team, who were not involved in analysing the 


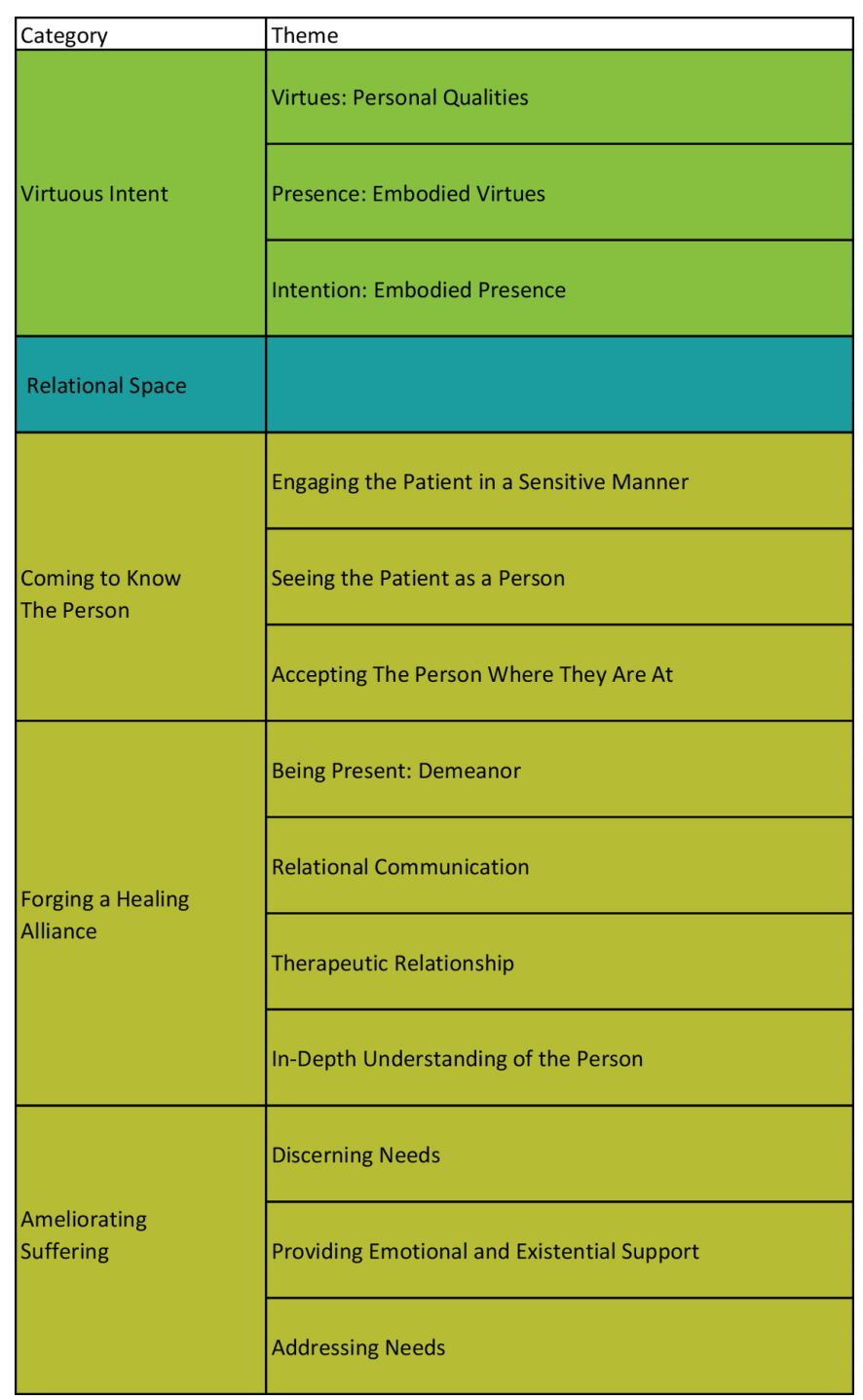

Figure 1 Elements of compassion: categories and themes.

interviews or focus groups, independently audit the coding process. Axial coding, the second stage of analysis, began at a 3-day face-to-face analysis team meeting after stage 1 focus group data had been analysed. The purpose of axial coding is to compare codes with other data, to combine and collapse codes, and to cluster codes into categories and themes. Axial coding generated a coding schema which was used and modified in subsequent interviews. The third stage of analysis, selective coding, involved integrating and refining categories and themes after the model and core variable were identified, delimiting coding to those categories that relate to the core variable. The model was finalised at a subsequent 3-day meeting and then vetted through the study participant and a key stakeholder focus group. This study met the 32 Consolidated criteria for Reporting Qualitative research. $^{43}$

\section{RESULTS}

Five categories and 13 associated themes emerged from the data (figure 1). The core variable, which describes phenomenon of interest and links the categories together, is: a virtuous, intentional response to know and understand a person and ameliorate their suffering. The key dimensions of compassionate care are illustrated in a model (figure 2), which generated an HCP definition of compassion: a virtuous and intentional response to know a person, to discern their needs and ameliorate their suffering through relational understanding and action.

\section{Virtuous intent}

Participants provided insight into the innate qualities which served as the catalyst that compassion flowed from and through. Compassion was not simply understood as an affective response, but a response based on the virtues that participants brought into the clinical encounter. The category of Virtuous Intent, the purposeful desire to embody and express one's good and noble qualities in professional practice, was described by several participants as an internal process of self/provider congruence.

\section{Virtues: personal qualities}

Study participants identified virtues as the primary motivator of compassion. While a few participants identified virtues as a collective whole, most participants listed individual virtues such as love, kindness, genuineness, care and peace which naturally distilled into this theme in an iterative manner. Virtues were conceptualised as the good character or noble qualities embodied within HCPs that stimulated compassion. In this study, virtues were not equated with morality, religion or spirituality, although some participants did identify these as potential facilitators; rather, they were human qualities that could be developed through a variety of other means including family upbringing, role modelling, self-reflection and life experience. As a result, while participants felt that every HCP possessed and could cultivate virtues, they acknowledged variation in these innate qualities based on personal and professional experiences, willingness and circumstance. While compassion was conceptualised as a multidimensional construct (figure 2), the other categories of the model had to flow through virtues of love, acceptance, honesty, genuineness, humility and kindness to be considered compassionate. Compassion's rootedness in HCPs' virtues was viewed by participants as a distinguishing feature of compassion in comparison to other expressions of care (eg, routine care, empathy, sympathy).

Genuine love for your fellow man, that helps you be compassionate and to want to care for people. (Interview Participant 3)

When I think of empathy and I think of compassion, I think that compassion is a bit broader and deeper and more loving. (Interview Participant 15)

I think you can say the right words, but I think there has to be genuineness behind it. And I think people pick up on that whether you're acting or not. (Interview Participant 7) 


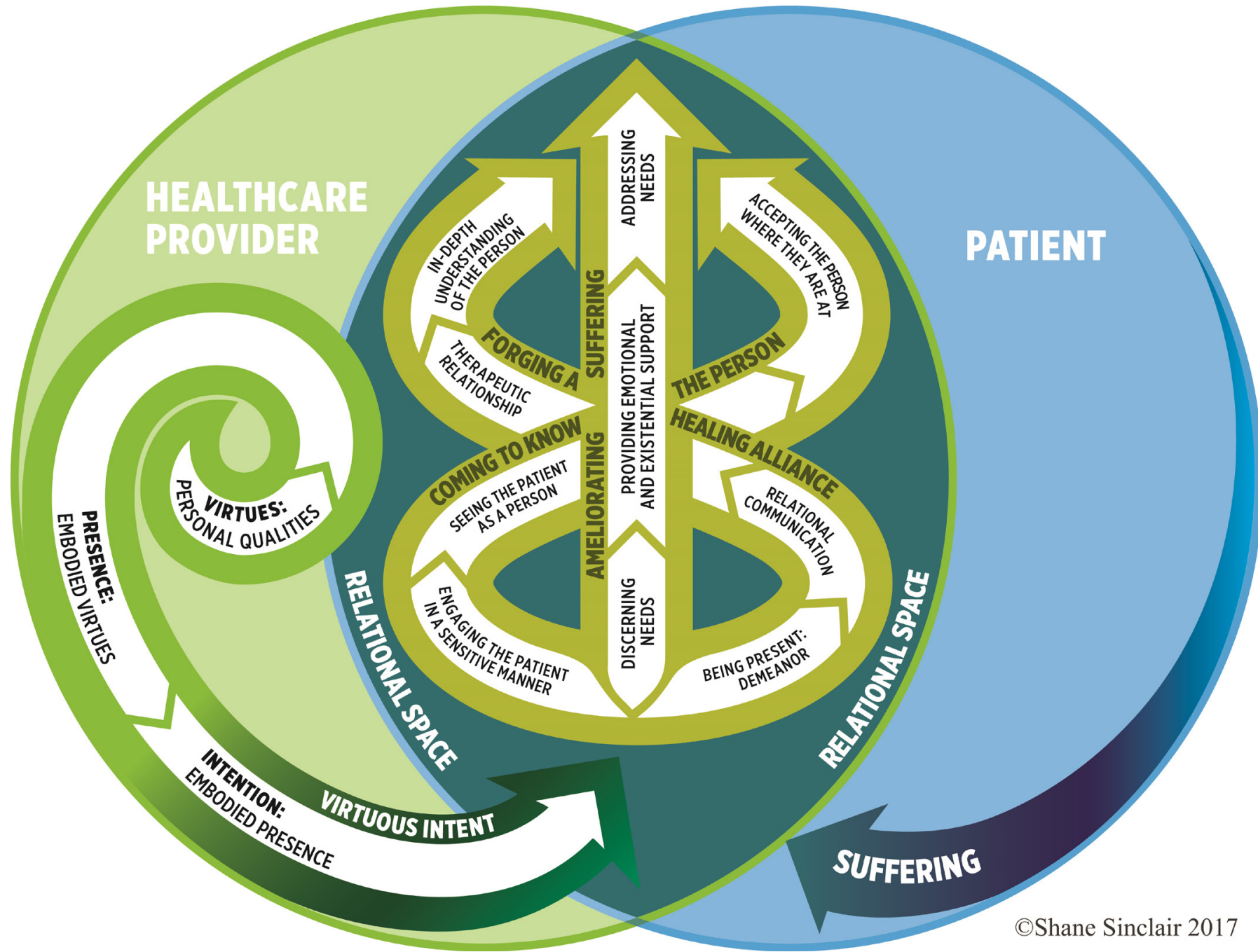

Figure 2 Healthcare Provider Compassion Model.

\section{Presence: embodied virtues}

Presence was understood as the distillation and expression of personal virtues to others through the character of an individual. In other words, according to participants, virtues in relation to compassion were not considered static traits, but needed to permeate through the presence of HCPs into their practice. Since HCPs felt that patients could intuitively sense their virtues and capacity for compassion, they emphasised the importance of self-awareness and developing these inner qualities prior to interacting with the patient.

There's something in the caregiver that resides in the caregiver but it's sort of, there's this catalytic thing that happens when it comes into the presence of someone else's suffering and then something could catch fire or not. (Stage 1 Focus Group Participant 12)

Being genuine, they can see that and they can feel that so... it's almost like an energy that occurs as well. They can feel it and you can feel it... I always say can I be vulnerable in their presence and try to equalize it and I don't necessarily disclose my human spirit but I think I release it in a way that allows them to bring it forward. (Stage 1 Focus Group Participant 23)

Before we ever say a word, people feel from us who we are, in these beds and in these rooms. And that's compassion. (Interview Participant 6)

\section{Intention: embodied presence}

Immediately prior to engaging with the person in suffering, many participants described an intentional practice, where they adopted a self-effacing and curious attitude towards the patient and tried to orientate themselves to the patient's perspective. In several participants, the necessity for a self-effacing attitude to compassionate care was explicitly described. In contrast, it was implicit in the responses of many of the exemplary compassionate caregivers, whom upon being notified that they had been nominated, spontaneously indicated that they did not self-identify as being particularly compassionate. This intentional process of concurrently demoting oneself and trying to take the perspective of the patient reflected participants' belief that compassion involves forethought and choice. Compassion was described as being conveyed through the virtues or energy that HCPs 
conveyed in interacting with a patient. Participants, however, were clear that this did not occur through happenstance, but through a process of self-reflection where HCPs drew awareness to their internal state and intentionally tried to put aside their own frustrations, needs, wishes and preconceptions about the patient in order to practise compassion.

Everyone has the possibility to be compassionate. They just have to choose to be. (Interview Participant 1)

It's almost like a different intentional way of being that you have to work on or cultivate. (Stage 3 Focus Group Participant 1)

I think compassion is about coming with an open, maybe even curious attitude of being able to be present with another individual... So being able to suspend what's going on for those few moments when you enter and so, you know it's kind of like you know envisioning as you approach the door and taking that deep breath and kind of cleansing yourself to walk into that room. (Interview Participant 8)

\section{Relational space}

Participants situated the core categories of compassionate care within a broader relational space, which was defined as the context for compassion where the virtuous intent of the caregiver engages the suffering of a person. Relational space differed from other categories in that it was not a mutually exclusive category, as the three categories 'Coming to Know the Person', 'Forging a Healing Alliance' and 'Ameliorating Suffering' were nested within it. This was due to participants' belief that compassion was embedded in a relational approach that traversed the three categories subsumed within it. Compassion was relational in that it was regulated by an openness by patients to receive compassion and a willingness on the part of the HCP to be professionally and personally impacted by the suffering of their patients.

Compassion involves two people or more I guess, but it's not just sort of one person I am being-I am exuding compassion. Like I think it needs to be given and received and I see it as kind of going back and forth. (Interview Participant 8)

It's not something that exists just within me. It's something that occurs between me and somebody else. (Interview Participant 1)

\section{Coming to know the person}

Having established an initial connection to their patient within the relational space, HCPs described an ongoing process of coming to know the person, an attentive and sensitive approach that seeks to engage, see, accept and understand the patient as a person.

\section{Engaging the patient in a sensitive manner}

HCPs described the importance of engaging the patient in an attentive and sensitive manner within the clinical encounter. This involved HCPs attuning to the energy of the room, the patient's presence and interpersonal cues in order to be attentive to the person and to develop an awareness of their background. Many participants felt that this approach allowed them to develop an appreciation of the patient's broader life story, to see the patient as a person and accept them where they were at.

This is the sensitive part you're matching their energy level for that time that they're in the hospice or that time you're in that room. (Interview Participant 12)

Sensitivity would probably be one of the-being able to read a room when you walk into it and kind of know what's going on or sense what's going on there and be sensitive to the dynamics that you feel between people there. (Interview Participant 1)

\section{Seeing the patient as a person}

In the context of clinical care, participants were emphatic about the importance of extending one's vision beyond the illness, the body and 'the patient' in order to view the person as a fellow human. Seeing the patient as a person ranged from simple gestures such as asking the person how they preferred to be addressed, to eliciting the person's story, to allowing the person to make care decisions versus telling them what to do.

I think what we need to do is we need to see this person as a human being... treat this person as a human being and not as the patient with diagnosis $\mathrm{X}$, but as a person who has had all of these lived experiences that is at this place and is feeling this way. (Interview Participant 8)

So, you need to look them in the eyes and be soft and kind and like 'I see you behind there.' And I'm going to take care of you, like I've got you, like I got this. (Interview Participant 15)

I think true compassion is you know an understanding individually of what is it that person wants and needs from us that we can give to them. (Interview Participant 2)

Accepting the person where they are at

Participants described a third theme that involved seeking to understand the person's circumstance and accept them unconditionally in spite of their past and/or present behaviours. This primarily involved accepting patient attitudes, behaviours and frustrations that were related to their situation. Extending unconditional acceptance towards abusive patients or individuals with a chequered past served as both the greatest challenges to compassion and case exemplars of their compassionate colleagues.

One of the nursing attendants told me one day how he had been with a patient for two days and this guy had been incontinent of stool and just messed himself again and he was unsteady and the nursing attendant was supporting the guy and cleaning him up and while he was back there cleaning the back of his legs his bowels let go again and this professional, without complaint, began to wash the guy again. And the man 
turned around and using a racial epithet cursed him, what are you doing back there you fuck, and again the man took it with humility and generosity of spirit and didn't strike back with words or actions but fulfilled his duty. That's a striking story of compassion. (Stage 1 Focus Group Participant 4)

We've had a holocaust survivor. We've had a German soldier you know, who was forced into doing things that they didn't want to do.... We have to have compassion all around for each person. (Interview Participant 2)

One example that comes to mind is a young woman, who was a prostitute... and I was working in the OR and people were talking over her in a very disparaging manner... and I remember my thought at the time was I don't think she thought as a little girl 'Gee, I'd like to be a prostitute when I grow up.' But stuff happened in her life that that's where she was. (Stage 3 Focus Group Participant 3)

\section{Forging a healing alliance}

Although participants felt that compassion did not require a pre-existing relationship, they nonetheless felt that compassion was further forged and optimised through the establishment of a therapeutic relationship-a relationship that is nurtured, that is cultivated through verbal and non-verbal communication that promotes healing through an in-depth understanding of the person and their unique experiences in order to personalise compassionate care. Four inter-related themes comprised the category of Forging a Healing Alliance: being present; relational communication; therapeutic relationship; and in-depth understanding of the person.

\section{Being present: demeanour}

While time was a factor in forging a healing alliance, participants also felt that it could be quickly established through the demeanour HCPs conveyed within each clinical encounter regardless of its duration. According to several participants, demeanour involved attempting to be fully present to the patient and was reflected in the way in which care is given-where their demeanour enriched each care interaction.

Because it's not what you do, it's the way you do things for people that is compassion. (Stage 1 Focus Group Participant 35)

She's [exemplary compassionate care nominee] fully present in every room and when caring for someone, she makes it seem like they're the only person she has to take care of. (Stage 1 Focus Group Participant 24)

He [nominee] provides comfort with his calm and gentle demeanor. (Stage 1 Focus Group Participant 15)

\section{Relational communication}

Relational communication was described as the establishment of a deeper understanding of the person and their individualised needs through active listening. The centrality of listening relative to compassion involved listening to what patients said, and also listening to the subtext of what was not being said-tone of voice, moments of silence and non-verbal cues that helped unmask hidden suffering.

I think when people feel heard and they feel like someone actually cares and actually is taking the time to listen that's what they interpret as being compassionate. (Interview Participant 7)

When they call I usually just drop everything and you listen to their tone of voice. I can hear it when the tears are there you know... there's that pause and I let that pause happen because they're deciding whether or not they're going to tell me or they're realizing how overwhelmed they really are. (Interview Participant 13)

It's listening to what's not being said and recognizing that and really gently making it okay to talk about those things. (Interview Participant 15)

\section{Therapeutic relationship}

The themes Being Present and Relational Communication were instrumental in establishing a deeper therapeutic relationship, which participants described as $a$ human-to-human connection facilitated through the mutual sharing of stories, feelings and expressions of care between HCPs and their patients in order to promote healing. Establishing a therapeutic relationship extended the largely unidirectional theme 'Seeing the Patient as a Person' to a reciprocal level, where participants related to their patients from a place of shared humanity.

He [physician nominee] tries to find out who they are and makes time for social visits not just medical assessments. (Stage 1 Focus Group Participant 29)

I really wanted to understand, but not from a head space, like from a heart space in terms of the feeling and really kind of connecting that way with her. (Interview Participant 15)

I try to have a sense of what story they're living and be able to kind of feel how I can be a constructive player in that story. (Interview Participant 1)

\section{In-depth understanding of the person}

The end outcome within the category of forging a healing alliance was to come to an in-depth understanding of the person, allowing HCPs to address a person's multifactorial needs in a personalised manner. Coming to an in-depth understanding of the person was conceptualised as a deep desire to engross oneself in a person's story in order to determine sources of personal meaning and how these were effected by and contributed to their suffering. Whereas the theme 'Intention' involved emotional resonance (feeling with), in which participants considered how they would want to be treated if they were in the patient's position, an in-depth understanding engaged a higher process of 
'feeling for' the patient. This involved moving beyond considering how the HCPs would want to be treated if they were the patient, to in having developed an in-depth understanding of the person-an understanding of how the patient would want to be treated.

The Golden Rule is good to a point, but sometimes somebody else might not want what I want. (Interview Participant 15)

What brings meaning to them and it's about how we engage and being able to support that. (Stage 1 Focus Group Participant 30)

\section{Ameliorating suffering}

The primacy of action within each of the categories of compassion culminated in participants identifying 'ameliorating suffering' as the ultimate goal of compassion. Ameliorating suffering was defined as tangible acts intended to alleviate actual or anticipatory threats to a person's physical, emotional, social and/or spiritual well-being.

\section{Discerning needs}

The theme Discerning Needs describes the ability to anticipate, perceive or prioritise healthcare needs based on knowledge of the person and their circumstance in order to alleviate their suffering. Discernment ranged from anticipating an impending pain crisis, to recognising the patient's need for personal space, preparing the patient for a prognostic conversation, demoting competing system priorities and prioritising which patients needed compassion the most.

One of the strategies that I usually employ is I try to think about at the beginning of the day, you know who needs the most time today? And then structure my day accordingly as much as possible... (Interview Participant 9)

The discerning needs piece really resonated with me, thinking back to my days as a bedside palliative care nurse... it's absolutely true, especially discerning which patients need more compassion. (Stage 3 Focus Group Participant 5)

Then that's where anticipatory care is really important, because you're like I've already thought of that. That's why I just gave him a break-through because he's looking like he was in pain and he has to go to radiation in half an hour. (Interview Participant 4)

\section{Providing emotional and existential support}

While compassion traversed the care trajectory, health domains and the caregiver/patient relationship, participants also identified key moments where compassion seemed to be essential or most needed-incidences of suffering that included emotional and existential distress. Providing emotional and existential support involved allaying uncertainty, fears and distress that threaten personal existence by eliciting meaningful memories, affirming strengths and providing supportive touch and words of affirmation.
To me it didn't seem humane that this gentleman was gonna die alone, it just didn't seem right that he'd had no visitors and now he was gonna leave this world alone. I don't know if he knew I was there but I just held his hand and talked softly. (Stage 1 Focus Group Participant 3)

I'm doing what I'm setting out to do and it's not only my job physically, but it's that bigger-maybe kind of total... but then there's a psychosocial, spiritual pain that they can be having. (Interview Participant 11)

I think that we can have all the words and have all the nice clothes and look like we've very efficient, but I think it's compassion that shakes the hand of another person and that rubs their forehead, that opens the door to their heart where they feel safe. (Interview Participant 6)

\section{Addressing needs}

The final theme, Addressing Needs, involved a proactive and attuned response to directly engage in and alleviate a person's multifactorial suffering. Participants expressed that compassion addressed needs primarily in two ways: small acts of compassion within HCPs' call of duty; and extraordinary acts beyond the call of duty. There were several specific examples of small acts of compassion identified. They included exercising diligence and sensitivity in routine care such as attending to activities of daily living; and demonstrating attention to detail in seemingly perfunctory activities such as filling out a patient's paperwork or conveying patient preferences at shift change. Addressing needs that fell outside of the call of duty or 'going the extra mile' were arguably the greatest indicators of a compassionate HCP and were the most frequently stated reason for peers to nominate their exemplary colleagues. In many ways, these extraordinary acts seemed to function as a litmus test to detect whether care was internally motivated from a place of virtues or an ulterior motivator such as remuneration, duty or social desirability.

I think that empathy is really understanding the feeling and perspective kind of or what is happening for that person. I think the compassion is taking that and translating it into an actionable item. (Interview Participant 15)

And the little things too, when people are in bed we ask them if they like ice water or room temperature water and it seems like a pretty minor thing but if you don't really like ice water and you have a jug of it at your bedside and that's all you have to drink that's not really compassion. (Stage 1 Focus Group Participant 8)

It's making sure that their paperwork is done and their paperwork is sent out and following up on things that maybe got dropped along the way... There's compassion in that too, because you want to make sure that the road is paved as smoothly for that family and that patient as possible. (Interview Participant 13) 
They stop at the cafe to get a bowl of soup that they know that that patient likes that bowl of soup. It has nothing to do with their job but they know that they're not eating and if they hear them say something that they like, they stop and pick it up... and they sit and eat with them. (Stage 1 Focus Group Participant 29)

\section{DISCUSSION}

Compassion is widely regarded as an essential part of quality healthcare. In contrast, the construct is still at an early stage of research development, with limited clinical studies describing how aspects of compassion can be operationalised in practice. The Healthcare Provider Compassion Model delineates the key dimensions of this dynamic construct and begins to address this theory-practice gap. We hope it will foster discussion as a pragmatic tool for evidence informed practice and as an empirical foundation for future studies in this area.

This study conceptualised compassion within healthcare from the perspective of HCPs, extending our previous research on patients' perspectives. ${ }^{19}$ While we had anticipated that the Healthcare Provider Compassion Model would be depicted in a distinct fashion to the Patient Compassion Model, ${ }^{19}$ our analysis revealed that while there were some differences at a thematic level, the core categories largely mirror the Patient Compassion Model-illustrating the flipside of the compassion dyad (figure 2). This was further verified by stage 3 participants, who provided face validity as they endorsed the structure and temporal flow of the model. The model parallels the sequential clinical process of a HCP approaching the bedside, making an initial relational connection, getting to know the person, forging a therapeutic alliance and then working to ameliorate suffering. While the model depicts a sequential flow of compassion between and within categories, stage 3 participants cautioned against a strict stepwise conceptualisation of compassion, noting that in reality there was oscillation across the model. In practice, this suggests that HCPs can revisit earlier themes within the model. For example, they likely reassess their intentions on an ongoing basis at each clinical interaction or come to a deeper acceptance of the person as the therapeutic relationship is strengthened. Likewise, while participants felt that each of the categories needed to be engaged for care to be considered compassionate, the three intertwined categories within the model's core illustrate that certain dimensions of compassion may be more prominent to others, while still reaching the same ultimate outcome-addressing a person's needs. For example, coming to know a person may be more prominent in admitting a stable patient to a care home, whereas ameliorating suffering will likely be more prominent when treating a patient with an acute pain crisis. These five dimensions depicted within the model are congruent with previous research, which identified compassion as a multidimensional construct consisting of clinical behaviours, communication skills, presence, understanding and emotional engagement. ${ }^{13}$ The current study extends this previous research by providing greater detail about the contents of these dimensions through the 13 themes contained within them, while also adding the Virtuous Intent dimension, identifying the pivotal role that virtues play in engendering a compassionate response within HCPs.

A multidimensional understanding of compassion adds depth to current constructs of compassion both at the bedside and in research. Much of the previous work has focused on unidimensional conceptualisations of compassion limiting it to a feeling, a trait or a virtue, producing corollary interventions to improve HCP affective components of compassion through contemplative practices and mindfulness training. ${ }^{94-46}$ Inarguably, interventions aimed at enhancing awareness of HCP attitudes and cultivating virtues of love, kindness, altruism and equanimity are essential to improve compassionate care. The current work offers the opportunity to augment these with training focused on clinical skills and behaviours reflecting the interdependent categories and themes on which compassionate care is grounded.

HCP participants provided insight into the internalised processes of compassion, which patients in our previous study could only postulate due to their limited perspective as the recipients of compassionate care. At a categorical level, these new findings resulted in the emergence of the broader category of 'Forging a Healing Alliance', with 'Relational Communication' being subsumed as a theme within it. The additional theme 'Therapeutic Relationship', along with the themes Demeanour and Relational Communication, emphasises HCPs' intent and the centrality of coming to an in-depth understanding of the patient as a person in compassion, affirming similar research in the field of psychology. ${ }^{2044}$

A more fulsome understanding of compassion at a thematic level emerged from this study, as according to HCPs, compassion was not a systemic form of caring, but an intentional, discerning and targeted modality. This affirms other researchers' work on the topic, who reported that compassion is not coincidental but involves choice $^{12} 134748$ and the downregulation of destructive HCP thoughts and behaviours. ${ }^{49}$ Considering this prior and current research, we suggest that compassion may be conceptualised through the lens of 'personalized healthcare', extending the concept of personalised medicine that focuses on tailoring the treatment of disease based on individual characteristics, ${ }^{50}$ to each interaction the patients have with their HCPs.

The themes 'Discerning needs' and 'Intention' raise additional questions regarding the unconditional nature of compassion. Previous research identified compassion as largely being an unconditional care construct, in comparison to the conditional nature of sympathy, which is mediated by the self-preservation of the caregiver, and empathy, which is effected by perceived relatedness and deservedness. ${ }^{39} 51 \quad 52$ According to HCPs, compassion involved bringing an 
open mind and not simply an empty head to each patient encounter, ${ }^{31} 53$ echoing Wilber's summation that, 'real compassion includes wisdom and so it makes judgments of care and concern. ${ }^{54}$ Results from the current study suggest that reasoning, as it relates to compassion, assesses individuals' needs and seeks to understand the person, in contrast to other care constructs that seem to focus more on assessing the individual and allowing this to determine how to act accordingly. In a similar vein, participants' identification that compassion involved choice is further evidence that while compassion involves cognitive processing, it is not selective. Rather, the practice of intentionality involved exposing and counteracting these subconscious conditions and barriers in order to accept the person in an unconditional manner-expanding ones' capacity for compassion in the process.

One of the surprising findings of this study was the identification of virtues, the good and noble qualities embedded within the character of HCPs, as the primary motivator of compassion-unexpectedly replicating the results of our patient study. ${ }^{19}$ Several HCPs went so far as to describe compassion as a process of self/provider congruence, where they attempted to integrate and cultivate their virtues into their professional practice. ${ }^{55}$ Leaders in healthcare practice, policy and education might appropriately ask: Can compassion be mandated, learnt and evaluated at the bedside? The current study suggests that this remains a challenging and controversial proposition as genuine compassion involves the personal qualities of HCP and extraordinary acts that go beyond standard practice, job expectations or routine care. While making healthcare more compassionate is a pressing need, doing so by requiring HCPs to act in a way that is perceived by patients as compassionate is disingenuous and antithetical to compassion, and leads to a standardised approach that denudes HCPs of personal expression and the opportunity to demonstrate care beyond what is expected. ${ }^{23-8}$

\section{Strengths and limitations}

This study has several strengths and limitations. Prior work in this field has broadly considered physician, patient and family, clinical situation and environmental factors which individually and transactionally contribute to compassion. ${ }^{14}{ }^{15}$ The current study seeks to expand on this work by delineating elements which are at the root of these factors, across a range of training backgrounds of physicians, other HCPs and support staff involved in the delivery of healthcare. This study also assesses the interdependence of these elements building on research describing dimensions of compassion based on the direct reports of nurses caring for older people with a chronic disease. ${ }^{12} 13$ The current study adds to this knowledge base in its interdisciplinary focus, inclusion of urban and rural populations, recruiting from multiple types of care settings, and the identification of the virtuous intent dimension, demonstrating that compassionate communication and action is informed and regulated by certain HCP qualities.

We recruited participants from a palliative care programme in order to study compassion. We recognise that while compassion is deemed an essential element of healthcare, and is central to the professional motivation of the majority of HCPs, it is inarguably of great relevance in a healthcare environment which provides care where suffering is prevalent. We reasoned that while team members in a palliative care setting do not have a monopoly on compassion, they share with other HCPs across other healthcare settings a deep professional respect for its relevance and importance.

This begs the question-Are the findings from this study generalisable to other healthcare settings? Palliative care is by nature a team-based environment, and each professional group within it contributes to the overall culture of care. Dissecting out the perspectives of specific healthcare professional groups within the team as being distinct from the team itself may ultimately be identified as a worthwhile approach to better understanding barriers and facilitators to compassion, but at present requires further research. It is known that physician barriers to compassion are different based on number of years of clinical experience and different medical specialties. ${ }^{14} 15$ We therefore reasoned that it was wise to first establish what is common, establishing the empirical foundation of the construct, allowing future studies to further validate its generalisability and transferability to other settings and specialties.

Further, while the snowball sampling technique of stage 1 participants nominating stage 2 interviewees was beneficial, it may have diminished the heterogeneity of the sample, as participants may have inadvertently nominated like-minded individuals. Similarly, the HCPs sampled in this study were predominately nurses and physicians. While reflecting the composition of an interdisciplinary team and being representative of the professional composition of healthcare as a whole, it may not adequately represent the views of other groups of professionals. Finally, while participants identified behaviours that were associated with compassion, these were not verified by observational data.

\section{Implications for research, policy and clinical practice}

The Healthcare Provider Compassion Model provides a foundation that defines compassion in healthcare and its provision at the bedside. It may lead to the development of clinical tools to cultivate the requisite knowledge, skills, behaviours and qualities to enhance compassionate care to others. For example, it could potentially inform the development of a patient-reported compassion measure or serve as a blueprint to develop targeted and evidence informed educational interventions for healthcare systems aiming to enhance patients' experiences of compassion specifically. ${ }^{17}$ 


\section{CONCLUSIONS}

This study provides HCPs, educators, researchers and policymakers with a multidimensional model of compassion. It identifies the knowledge, skills, behaviours and qualities which underpin delivery of compassionate healthcare at the bedside. The systematic nature of the Healthcare Provider Compassion Model characterises the components of compassion and their inter-relatedness. There is also an element of flexibility within these domains that recognises that true compassion comes from within the person, through a dynamic human interaction with a patient and the patient's needs. While mastery may be unattainable, the multidimensional facets of compassion can potentially be nurtured in individual HCPs and throughout the cultures they work within.

\section{Author affiliations}

${ }^{1}$ Faculty of Nursing, University of Calgary, Calgary, Alberta, Canada

${ }^{2}$ Department of Oncology, Cumming School of Medicine, University of Calgary, Calgary, Alberta, Canada

${ }^{3}$ Research Institute in Oncology and Hematology, CancerCare Manitoba, Winnipeg, Manitoba, Canada

${ }^{4}$ College of Nursing, Rady Faculty of Health Sciences, University of Manitoba, Winnipeg, Manitoba, Canada

${ }^{5}$ Psychosocial Oncology and Cancer Nursing Research, St. Boniface Research Centre, Winnipeg, Manitoba, Canada

${ }^{6}$ School of Nursing and Institute on Aging and Lifelong Health, University of Victoria, Victoria, British Columbia, Canada

${ }^{7}$ Departments of Clinical Neurosciences and Medicine, Cumming School of Medicine, University of Calgary, Calgary, Alberta, Canada

${ }^{8}$ Palliative/End of Life Care, Calgary Zone, Alberta Health Services, Calgary, Alberta, Canada

${ }^{9}$ Department of Psychiatry, University of Manitoba, Winnipeg, Manitoba, Canada

Acknowledgements We acknowledge and thank the MSI Foundation for funding this study and the University of Calgary University Relations who designed the Healthcare Provider Compassion Model. We acknowledge Kate Beamer, research assistant, for her dedication and commitment to this study. We also acknowledge and thank the research participants who generously shared their time, wisdom, experiences and enthusiasm on the topic.

Contributors SS, SRB, TFH, SM, KS, AS, NAH and HMC conceptualised the study. SS supervised PS who managed, acquired, cleaned and coordinated the analysis of data. SS, SRB, TFH, SM, KS and PS analysed the interview and focus group data. All authors contributed to the final draft and approved the final version for publication.

Funding This study was supported by an MSI Foundation Grant (grant number 880).

Competing interests None declared.

Patient consent Not required.

Ethics approval Conjoint Health Research Ethics Board, University of Calgary (REB 15-1999).

Provenance and peer review Not commissioned; externally peer reviewed.

Data sharing statement № additional data are available.

Open Access This is an Open Access article distributed in accordance with the Creative Commons Attribution Non Commercial (CC BY-NC 4.0) license, which permits others to distribute, remix, adapt, build upon this work non-commercially, and license their derivative works on different terms, provided the original work is properly cited and the use is non-commercial. See: http://creativecommons.org/ licenses/by-nc/4.0/

(C) Article author(s) (or their employer(s) unless otherwise stated in the text of the article) 2018. All rights reserved. No commercial use is permitted unless otherwise expressly granted.

\section{REFERENCES}

1. American Medical Association. Code of medical ethics. $2006 \mathrm{https}: / /$ www.ama-assn.org/about-us/code-medical-ethics (accessed $23 \mathrm{Feb}$ 2017).

2. Department of Health. Confidence in caring: a framework for best practice. $2008 \mathrm{http} / / /$ webarchive.nationalarchives.gov. uk/+/www.dh.gov.uk/en/Publicationsandstatistics/Publications/ PublicationsPolicyAndGuidance/DH_086387? IdcService=GET_FILE\& dID $=144574 \&$ Rendition=Web (accessed 4 Aug 2017).

3. Flocke SA, Miller WL, Crabtree BF. Relationships between physician practice style, patient satisfaction, and attributes of primary care. $J$ Fam Pract 2002;51:835-40.

4. Paterson R. Can we mandate compassion? Hastings Cent Rep 2011;41:20-3.

5. MacLean L. The Vale of Leven Hospital Inquiry Report. $2014 \mathrm{http}: / /$ www.valeoflevenhospitalinquiry.org/Report/j156505.pdf (accessed May 2 2017).

6. The Willis Commission. Quality with compassion: the future of nursing education. Report of the Willis Commission on Nursing Education. $2012 \mathrm{https} / / / w w w . n u r s i n g t i m e s . n e t / d o w n l o a d ? a c=$ 1255026 (accessed 2 May 2017).

7. Department of Health. More care, less pathway- A review of the Liverpool care pathway. 2013 https://www.gov.uk/government/ uploads/system/uploads/attachment_data/file/212450/Liverpool_ Care Pathway.pdf (accessed May 2 2017)

8. Francis R. Report of the Mid Staffordshire NHS Foundation Trust public inquiry The Stationary Office: London, England;. $2013 \mathrm{https}: / /$ www.gov.uk/government/publications/report-of-the-mid-staffordshirenhs-foundation-trust-public-inquiry (accessed 4 Aug 2017).

9. Sinclair S, Norris JM, McConnell SJ, et al. Compassion: a scoping review of the healthcare literature. BMC Palliat Care 2016;15:6.

10. Papadopoulos I, Zorba A, Koulouglioti C, et al. International study on nurses' views and experiences of compassion. Int Nurs Rev 2016;63:395-405.

11. Papadopoulos I, Taylor G, Ali S, et al. Exploring Nurses' Meaning and Experiences of Compassion: An International Online Survey Involving 15 Countries. J Transcult Nurs 2017;28.

12. van der Cingel M. Compassion and professional care: exploring the domain. Nurs Philos 2009;10:124-36.

13. van der Cingel M. Compassion in care: a qualitative study of older people with a chronic disease and nurses. Nurs Ethics 2011;18:672-85.

14. Fernando AT, Consedine NS. Beyond compassion fatigue: the transactional model of physician compassion. J Pain Symptom Manage 2014;48:289-98.

15. Fernando AT, Consedine NS. Barriers to Medical Compassion as a Function of Experience and Specialization: Psychiatry, Pediatrics, Internal Medicine, Surgery, and General Practice. J Pain Symptom Manage 2017;53:979-87.

16. Streiner DL, Norman GR, Cairney J. Health measurement scales: a practical guide to their development and use. 5th edn. Oxford: Oxford University Press, 2015

17. Sinclair S, Russell LB, Hack TF, et al. Measuring Compassion in Healthcare: A Comprehensive and Critical Review. Patient 2017;10:389-405.

18. Beattie M, Murphy DJ, Atherton I, et al. Instruments to measure patient experience of healthcare quality in hospitals: a systematic review. Syst Rev 2015;4:97.

19. Sinclair S, McClement S, Raffin-Bouchal S, et al. Compassion in Health Care: An Empirical Model. J Pain Symptom Manage 2016;51:193-203.

20. Vivino BL, Thompson BJ, Hill CE, et al. Compassion in psychotherapy: the perspective of therapists nominated as compassionate. Psychother Res 2009;19:157-71.

21. Way D, Tracy SJ. Conceptualizing compassion as recognizing, relating and (re) acting: A qualitative study of compassionate communication at hospice. ComM 2012.

22. Ghaljeh M, Iranmanesh S, Nayeri ND, et al. Compassion and care at the end of life: oncology nurses' experiences in South-East Iran. Int $J$ Palliat Nurs 2016;22:588-97.

23. Lown BA, Rosen J, Marttila J. An agenda for improving compassionate care: a survey shows about half of patients say such care is missing. Health Aff 2011;30:1772-8.

24. Graber DR, Mitcham MD. Compassionate clinicians: take patient care beyond the ordinary. Holist Nurs Pract 2004;18:87-94.

25. Kvangarsnes $M$, et al. Nurses' Perspectives on Compassionate Care for Patients with Exacerbated Chronic Obstructive Pulmonary Disease. J Allergy Ther 2013;04.

26. Lloyd M, Carson A. Making compassion count: equal recognition and authentic involvement in mental health care. Int $J$ Consum Stud 2011;35:616-21. 
27. Bray L, O'Brien MR, Kirton J, et al. The role of professional education in developing compassionate practitioners: a mixed methods study exploring the perceptions xof health professionals and preregistration students. Nurse Educ Today 2014;34:480-6.

28. Armstrong $\mathrm{AE}$, Parsons $\mathrm{S}$, Barker PJ. An inquiry into moral virtues, especially compassion, in psychiatric nurses: findings from a Delphi study. J Psychiatr Ment Health Nurs 2000;7:297-306.

29. Skaff KO, Toumey CP, Rapp D, et al. Measuring compassion in physician assistants. JAAPA 2003;16:31-6, 39-40.

30. Horsburgh D, Ross J. Care and compassion: the experiences of newly qualified staff nurses. J Clin Nurs 2013;22:1124-32.

31. Department of Health. Compassion in Practice. Nursing, Midwifery and Care Staff. Our Vision and Strategy. 2012 https://www.england. nhs.uk/wp-content/uploads/2012/12/compassion-in-practice.pdf (accessed May 2 2017).

32. Kneafsey R, Brown S, Sein K, et al. A qualitative study of key stakeholders' perspectives on compassion in healthcare and the development of a framework for compassionate interpersonal relations. J Clin Nurs 2016;25:70-9.

33. McCaffrey G, McConnell S. Compassion: a critical review of peerreviewed nursing literature. J Clin Nurs 2015;24:3006-15.

34. Perez-Bret E, Altisent R, Rocafort J. Definition of compassion in healthcare: a systematic literature review. Int $J$ Palliat Nurs 2016;22:599-606.

35. R. F. Report of the Mid Staffordshire NHS Foundation Trust public inquiry. London: The Stationary office, 2013.

36. Callwood A, Cooke D, Allan H. Developing and piloting the multiple mini-interview in pre-registration student midwife selection in a UK setting. Nurse Educ Today 2014;34:1450-4.

37. Willis L. Raising the Bar. Shape of Caring: A Review of the Future Education and Training of Registered Nurses and Care Assistants. 2015 (accessed May 2 2017).

38. Strauss AL, Corbin JM. Basics of qualitative research: grounded theory procedures and techniques. Newbury Park, Calif: Sage Publications, 1990

39. Sinclair S, Beamer K, Hack TF, et al. Sympathy, empathy, and compassion: A grounded theory study of palliative care patients' understandings, experiences, and preferences. Palliat Med 2017;31:437-47.
40. Sinclair S, Torres MB, Raffin-Bouchal S, et al. Compassion training in healthcare: what are patients' perspectives on training healthcare providers? BMC Med Educ 2016;16:169.

41. Glaser BG, Strauss AL. The discovery of grounded theory; strategies for qualitative research. Chicago: Aldine Pub. Co, 1967.

42. Corbin JM, Strauss AL. Basics of qualitative research: techniques and procedures for developing grounded theory. Fourth edn. Los Angeles: SAGE, 2015

43. Tong A, Sainsbury P, Craig J. Consolidated criteria for reporting qualitative research (COREQ): a 32-item checklist for interviews and focus groups. Int J Qual Health Care 2007;19:349-57.

44. Gilbert P. The origins and nature of compassion focused therapy. $\mathrm{Br}$ $J$ Clin Psychol 2014;53:6-41.

45. Jazaieri H, Jinpa GT, McGonigal K, et al. Enhancing Compassion: A Randomized Controlled Trial of a Compassion Cultivation Training Program. J Happiness Stud 2013;14:1113-26.

46. Seppala EM, Hutcherson CA, Nguyen DTH, et al. Loving-kindness meditation: a tool to improve healthcare provider compassion, resilience, and patient care. J Compassionate Health Care 2014;1:5.

47. van der Cingel M. Compassion: the missing link in quality of care. Nurse Educ Today 2014;34:1253-7.

48. Zamanzadeh V, Valizadeh L, Rahmani A, et al. Factors facilitating nurses to deliver compassionate care: a qualitative study. Scand $J$ Caring Sci 2017.

49. Halifax J. A heuristic model of enactive compassion. Curr Opin Support Palliat Care 2012;6:228-35.

50. Stratified SR. personalised, or precision medicine. The BMJ Opinion 2012.

51. Singer T, Klimecki OM. Empathy and compassion. Curr Biol 2014;24:R875-8.

52. Post SG, Ng LE, Fischel JE, et al. Routine, empathic and compassionate patient care: definitions, development, obstacles, education and beneficiaries. J Eval Clin Pract 2014;20:872-80.

53. Bloom P. Against Empathy: The Case for Rational Compassion. New York: Harper Collins, 2016

54. Wilber K. One Taste: Daily Reflections on Integral Spirituality. Colorado, United States: Shambhala Publications, 2000.

55. Rogers CR. A Theory of Therapy, Personality, and Interpersonal Relationships: As Developed in the Client-centered Framework. New York, NY: McGraw-Hill, 1959. 